\title{
THE ELIMINATION OF FEEBLE-MINDEDNESS
}

\author{
By Henry Herbert Goddard, Ph.D., \\ The Training School, Vineland, N. J.
}

Feeble-mindedness may be defined as a state of mental defect from birth or from an early age due to incomplete or abnormal development, in consequence of which the person afflicted is incapable of performing his duties as a member of society in the position of life to which he is born. There are according to the most careful and reasonable estimates in the United States about three hundred thousand persons who would come under this definition. These are conveniently divided into three groups: (a) lowest, or idiots, $(b)$ middle group, or imbeciles, and $(c)$ highest group, formerly called the feeble-minded in a specific sense, but to whom we are now giving the name of moron.

The following definitions of these groups were given by the Royal College of Physicians of London, and were adopted by the Royal Commission on the Feeble-Minded as a basis of classification. The idiot is defined as "a person so deeply defective in mind from birth or from an early age that he is unable to guard himself against common physical dangers." The imbecile is defined as "one who by reason of mental defect existing from birth or from an early age is incapable of earning his own living, but is capable of guarding himself against common physical dangers." While the moron is defined as "one who is capable of earning his living under favorable circumstances, but is incapable from mental defect existing from birth or from an early age, $(a)$ of competing on equal terms with his normal fellows, or $(b)$ of managing himself and his affairs with ordinary prudence."

\section{Why We Should Eliminate Feeble-Mindedness}

The part of feeble-mindedness that comes under the term "idiocy" comprises a group of helpless children who are no comfort to themselves and no comfort to their parents or caretakers. Of all pitiable humanity probably the idiot comes in for the largest share of sympathy from those who see him. He is a source of expense ( 505$)$ 
and trouble. No matter how freely the trouble may be met by those nearest of kin, it is nevertheless true, that a child so afflicted is a constant source of unpleasantness and unhappiness to all those who have to do with him. Surely every one would say, if it is possible to eliminate this kind of feeble-mindedness it must be done. Nevertheless, as we shall see later, this is of all the groups the least objectionable and the least dangerous.

The group called "imbeciles" comprises those persons who are usually recognized as silly, foolish, or stupid. They can, if wisely trained be made to do some work and be a little helpful. But they are always a menace to society because it can never be determined beforehand when any one of them may yield to any of his natural impulses and destroy life or property. Society must set a large army of teachers, trainers, or attendants to watch over and care for these, or be in continual danger of injury or even destruction at the hand of this irresponsible group. The elimination of this grade of feeble-mindedness would result in an enormous improvement in happiness and possibilities of achievement in every community.

The highest group, the "moron," comprises those persons who to the superficial view are often considered normal but somewhat backward or dull. As the definition tells us, there are two characteristics of these people. The first is that they are unable to compete on equal terms with their fellows; and, second, they are unable to manage their affairs with ordinary prudence. The result of the second characteristic is that again it requires a large army of people to take care of these morons, and to see that their affairs are managed with prudence. In the past it has been difficult to provide for this class in this way because the ordinary person, not recognizing this as a form of feeble-mindedness is unwilling to interfere in the affairs of such an individual and manage them for him, as ought to be done. In consequence of these two characteristics of the moron, he becomes an enormous drag upon society, and the elimination of this grade of feeble-mindedness wottld be the greatest boon of all. Being unable to compete on equal terms with his normal fellows, he is always either an object of charity or a dishonest person. Not being able to earn a living from his own honest efforts, he either becomes a beggar and pauper, living more or less at public expense, unless indeed, he has relatives who are willing to supplement what little he may earn and so help out his existence, or else he turns to dis- 
honest practices in order to get that which he needs for a living. And this is the most innocent form in which his defect shows itself. In other cases his natural instincts, however vile they may be, express themselves to the full becatise he has no power of control over them, and they easily turn him to crime. He becomes a criminal of the lowest sort, and in all these ways he becomes a serious menace to society, as he logically must.

But this is not only a matter of logic; facts may be produced to show that this is what actually happens. It has been found by some studies not yet published by the Galton Laboratory in England that paupers are found in the almshouses who are the children of paupers that were there before them, and they in turn were preceded by their pauper parents. In all probability we have here only another case of mental deficiency. Every one who has had to do with criminals in our jails and prisons recognizes that a large per cent of them are mentally defective, while those who have made any observations at all upon the prostitutes recognize that here also a considerable percentage are feeble-minded, and have simply fallen into this form of life because they could not make a living in any honest way, and because they easily became the victims of others who have had designs upon them.

These are the people who cannot be taught decent living, and through their ignorance of things, which they have not the capacity to learn, they spread disease, through their person and their untidy surroundings. They are thus a menace to public health as well as to morals.

Thus it is positively proved that the elimination of this type of feeble-mindedness would save us a large percentage of our pauperism, of our crime, and of prostitution, to say nothing of the large army of the ne'er-do-wells that are known all about us; and, again, of those persons who are known to be defective, but are cared for in their own families and make no demands upon the public.

The relative number of the different types is very uncertain because we have had until recently no accurate means of determining the grade or degree of defect, but it is perhaps not far wrong if we assume that we have twenty-five per cent. in the idiot grade, fifty per cent. in the imbecile grade, and twenty-five per cent. in the moron. If any correction is to be made to this estimate, it is probable that there are rather less idiots and rather more morons. 
A study recently made by the Vineland Laboratory of the mental development of the children in an entire school system of 2,000 children shows three per cent. of the first five grades to be feebleminded; fifteen per cent. were two and three years backward; seventy-eight per cent. were normal, and four per cent. were supernormal.

\section{Can We Eliminate Feeble-Mindedness?}

We may consider this question from two standpoints: first, can we eliminate feeble-mindedness without eliminating the feebleminded; or in other words, can a feeble-minded person be cured? Since Seguin, very few persons who have studied the problem have been willing to give anything but a negative answer to this question. Indeed, it is usually stated very emphatically that a person once feeble-minded is feeble-minded always. But if we look at the question in the broadest way we have to confess that our sole reason for saying that these children are incurable is that they never have been cured. It is quite a different thing from being able to say with authority that they never can be cured.

In the case of the lowest grade, it is true, we have no reason to hope for anything else. While very little anatomical study has been made, what has been made has given rise to the conviction that there are deficiencies in brain tissue, such that normal mentality could not be produced under any circumstances. But the same thing cannot be said of the higher grades. Indeed, our ignorance of anatomical conditions is so great that no one can say positively that the feeble-mindedness in some proportion of the moron type is not due to conditions which might be easily changed if we understood them.

Recent findings in the Vineland Laboratory seem to indicate that in some cases these children may be perfectly normal to quite a late age of childhood, possibly eight or ten years. If this proves to be the case, then comes the very insistent question, Why may we not learn how to so treat these children in early years as to prevent the onset of this condition later?

By the thyroid treatment it has been possible to restore the cretin from the imbecile type to perfect normal conditions, both physically and mentally. If such a result is possible in this particular type may not something else be discovered which will work similar results in other types? The very thought of the possibility of this 
suggests the enormous need of greater research along these lines. Society might spend millions in the study of this problem, and the efforts to eliminate feeble-mindedness in this manner. Even if the results were negative and it were discovered that it is impossible they would be well worth having. But until we have studied the question and found out the actual condition, we are groping blindly in the dark.

Should it eventually be proved that our guesses are true and that feeble-mindedness is the result of an inherited defect, that can not be changed, then our problem shifts to the other side, and we must ask ourselves, can we eliminate feeble-mindedness by eliminating the feeble-minded. This, of course, must mean the prevention of the production of feeble-minded persons and not the destruction of such persons after they are born. For while the thought does rise in the mind of most any visitor who looks at a room full of idiots, "Oh, that these persons might be quietly put to sleep and put out of this wretched condition," yet when we attempt to face such a thing practically we find that not only our hearts, but our heads, revolt from such a thought. Humanity, because it is humanity, can never resort to such a procedure, and a child once born into the world must live its life until it passes out by natural means and against all the reasonable efforts that we can devise to keep it alive.

Turning our attention then to the prevention of the birth of feeble-minded persons, we have several lines to consider. In the first place, we have to review the various known causes of mental defect. We have, first, two great groups, the feeble-mindedness that is hereditary, and the feeble-mindedness that is the result of environment. Under the latter head we have possibly the following causes: malnutrition, epileptic and infantile convulsions, toxic, primogeniture, traumatic, premature birth, abnormalities of labor, injuries to the fetus, abnormal conditions of the mother during pregnancymental and physical, the age of the parents, consanguinity, syphilis, tuberculosis, alcoholism, and disease of the nervous system. It will be seen that we have taken environment in the broadest sense to include everything that may cause mental defect which is not true heredity. In the other group we have those cases where the child is feeble-minded for no other reason than that the parent or grandparent was feeble-minded; in other words, the case of true inheritance. 
I have also mentioned in the environment list several things that studies show are not causes. They are included here because they are popularly thought to be causes. Consanguinity is perhaps the most striking illustration of this. Age of parents may be another; also primogeniture, and premature birth, while other things mentioned in this list are still either in doubt or are known to have a very slight influence. But whether the influence be slight or much it is evident that we can if we know enough change the environment; and the conditions which often produce feeble-mindedness may be eliminated, thereby eliminating the mental defect. But all these causes combined are small compared to the one causeheredity. The vast majority of feeble-minded persons are so because parent or grandparent was feeble-minded and there is true inheritance.

The following two charts, illustrative of a large number, show what we mean: Chart I shows the feeble-minded grandchildren of a feeble-minded grandmother. Chart II shows the feeble-minded children of a feeble-minded father.

Often we have charts upon which half the persons represented are feeble-minded. Can we eradicate feeble-mindedness in this hereditary form?

If a farmer has a breed of cattle that he no longer desires he has simply to cease breeding from this stock and the race dies out. We know that many species in nature have died out. And so here, if we have in the feeble-minded race an undesirable variant from the normal, we can, if we will, interfere and see to it that this race does not perpetuate itself. So the answer to the question, can we eliminate the feeble-minded, is answerable in the affirmative. It is true that a certain amount of feeble-mindedness is accidental, and accidents will always occur, so that we may not look forward to a time when there will not be a certain number of feeble-minded persons, but they will be in such a small proportion as to be practically a negligible quantity.

\section{How Shall We Eliminate the Feeble-Minded?}

As already implied, the only way to eliminate the group of feebleminded due to environmental conditions is to change the environment. If feeble-mindedness is sometimes due to abnormal conditions of the mother during pregnancy, we must study the problem and 
understand the situation at that time, so that abnormal conditions may not exist. If epileptic convulsions produce feeble-mindedness we must learn to control epilepsy, and so on through the list. All this again implies that we need an enormous amount of study to manage this problem, for as yet we are absolutely ignorant on nearly all of these points, but the possibilities of eliminating this group of
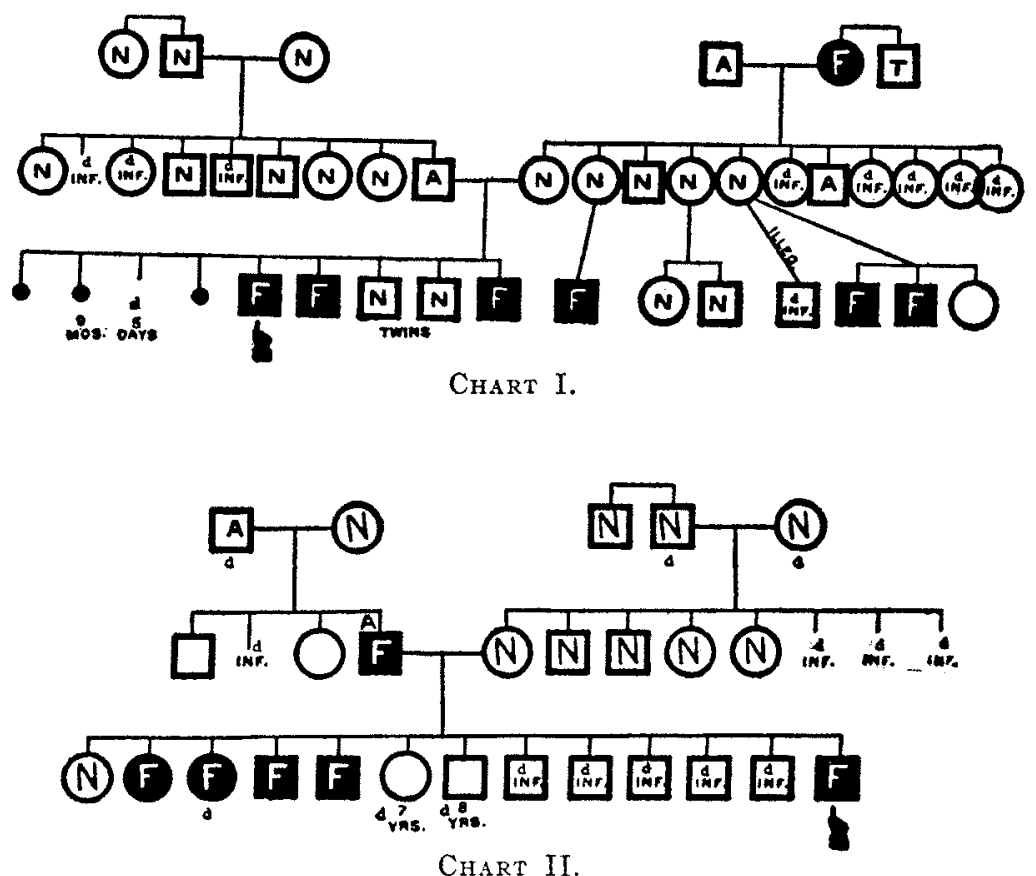

Key to Charts.

Square indicates male. Circle indicates female. A, alcoholic (habitual drunkard). F, feeble-minded; $N$, normal; $T$, tuberculous; small black circle indicates miscarriage; $b=$ born; $d=d i e d ;$ inf.=infancy; illeg.=illegitimate; hand shows which child is in the institution for the feeble-minded.

the feeble-minded is not to be denied, and the method is plain when once we have learned the facts.

All this sort of feeble-mindedness ought to be eliminated, and some day will be, but on the other hand this is actually only a small percentage of feeble-mindedness, as shown above. The feeble- 
mindedness of the greatest group is hereditary, and the cause of such feeble-mindedness is the feeble-minded parent or grandparent, and our problem here takes another turn.

As we face the question, "can we prevent children being born of persons who are feeble minded?" there are two possible methods. The first would be to keep the sexes apart; and the second to render them incapable of reproduction.

The first of these is discussed usually under the head of permanent custodial care. This means that society must set to work to cliscover all of these feeble-minded persons, and as rapidly as possible segregate them in colonies where the sexes are kept absolutely apart so that every feeble-minded male and every feebleminded female is compelled to live his or her life in conditions of absolute sexual seclusion. If this were done, we would have in a single generation all of the hereditary cases taken care of except those that arise sporadically from the free variation in the stock, and this would be comparatively small.

Every one admits that permanent custodial care is the ideal solution of the problem, both from the standpoint of effectiveness and from the standpoint of the humanity of the case. The great objection or difficulty that arises in connection with this, and is usually considered insurmountable, includes the item of expense involved, and, second, the difficulty to getting all of these people into a colony and under the control of those who have sufficient intelligence.

The first of these arguments is fallacious. The cost of such a procedure would be large, but it would not be as large as the present cost to society for the care of these same persons, to say nothing of their progeny in future generations. Colonies for these feebleminded would to a large extent take the place of prisons and almshouses, with the advantage that the persons in these colonies could be trained to more or less useful work under the supervision of experts, whereas the inmates of our present institutions for the poor and the criminals are practically of no use to society.

One must also refer to the sentimental reason that is often met with that it is cruel, or at least unpleasant, to think of placing these children in institutions. To this it must be replied there are institutions and institutions. Any one who cares to investigate the matter may discover for himself that it is possible to have institutions 
for the feeble-minded that are the happiest places in the world. It is possible to help these people to live a life of complete happiness in proportion to their mental attainments. And one cannot visit our best managed institutions without going away with the firm conviction that it is possible to colonize all of our feeble-minded persons under conditions in which they would be perfectly happy. Thus any objections that seem to occur from the feeling that it is treating them badly are at once eradicated. Such ideal institutions would also very largely eliminate the difficulty of inducing parents to give their consent to the transfer of their defective child to an institution. However, the success of such a plan is not dependent upon the consent of the parents. Even though society finds itself unwilling forcibly to deprive the parents of their feeble-minded child, there is still a possibility. If parents are unwilling for their child to be transferred to such a colony, the child may be trained in the public school by methods that are suited to his mental condition. He may be guarded by his teachers and the probation officers or some person similar who keeps his eye upon such a child while he is at home. After he has left school, if he leaves it, and upon the slightest indication that he is going wrong, is thinking of marrying, or is in danger of becoming a parent out of matrimony, the State may then interfere, and take the child to the colony home. Such a procedure may be managed in such a way as not to offend our most sensitive feelings for justice to the defective.

This is not the place to go further into details, and show how such a plan may be worked out with entire success and at a cost that is well within the means of any Commonwealth, and that it would be cheaper in money, more economical in social life, and of immense value morally. Time does not permit me to even extend the argument, and show that this colony idea is the ideal one not only from this standpoint of the reproduction of the species, but also from that of the welfare of the person and of society.

As was said earlier in this paper, these persons are all and always a menace to society. Aside from the tremendous menace of procreating their kind, it can never be predicted when one of them may commit crime or do some action innocent to him because of his irresponsibility, but which results in loss of property or life. All of these things make it of the utmost desirability that these children be segregated from normal society, and be placed in an 
environment that not only makes them happy, but makes them safe from their own defect, and makes other persons safe.

There is left for consideration treatment for rendering all feeble-minded persons incapable of perpetuating the species-what is spoken of as sterilization, asexualization, or unsexing. Some method for this must undoubtedly be considered and practiced to a greater or less extent, but it must be remembered that it is a makeshift. Such a procedure is very far from being an ideal solution of the difficulty. For reasons already mentioned these persons should be segregated from normal people, and if they are to be segregated and colonized in a place where they can be cared for, and trained and made happy, any other method is unnecessary, the problem is solved without it. However, it is possible that conditions have become so bad that we must seize upon everything that offers hope of relief. We have taken such good care of these people for so many years, have allowed our humanity to get so far ahead of our judgment and reason that we have turned loose in the community a large body of strong men and women, well developed physically, but who have this hereditary taint of feeble-mindedness. As a result, feebleminded children are being born at such a rate that the mere mechanical problem of constructing buildings fast enough to take care of them is serious, so serious that we must resort to some method as a make-shift to help us out of the difficulty, and get us on our feet and place us where we can control the situation. There is no question that there should be a carefully worded sterilization law upon the statute book of every State, and that the practice should be carried on judiciously and carefully, but persistently all over our country, in order, as we have already said, that we may thus help to get control of the situation.

Two States have already passed such laws. Several other States have introduced such bills, but they have usually failed by a small margin to become law.

When we come to practicing some method of sterilization we are again brought face to face with our ignorance of methods and results. We have first, of course, the old and time-honored method of castrating the males and ovariotomy for the females. This is an efficient method, and as far as males are concerned, entirely safe. The only objection to it seems to be a sentimental one. Just what are the consequences, the metabolic changes in the individual as a re- 
sult of this operation, is not known with any high degree of scientific accuracy. Nevertheless, there are no indications that there are any serious consequences. The practice would accomplish great good in this line.

It must be admitted, however, that the operation on the female is a somewhat more serious one, and can hardly be practiced on any large scale without some danger of fatalities in a small percentage of the cases. Perhaps this is not greater than occurs in such operations as appendicitis to which normal people submit daily.

Recently a new method has come into the field which has a few very ardent advocates, particularly as far as the male is concerned. The operation is known as vasectomy. It is very simple, and may be performed in a few minutes in the physician's office, and with no other effect on the individual or his activities than the absolute prevention of procreation. It is even claimed that the result of this is a decided tonic effect upon the individual.

The analogous operation upon the female, that of tying the fallopian tubes, is more difficult than the operation on the males, and as yet no method of performing it has been discovered that avoids abdominal section with its concurrent dangers.

Biologists hold out some slight hope that methods of sterilization by X-rays may yet be discovered and become practical. However, that is still so far in the future that it is not worth the space to discuss it here.

It is noteworthy in all these methods that any operation is much more difficult on the female than on the male. This is a crucial point, because even if we are content with a partial result, the sterilization of the feeble-minded males does not begin to halve the difficulty. Experience shows that there are many more normal men who will marrry or live out of wedlock with feeble-minded women than vice versa, and consequently, unless something can be done to sterilize the female, our problem of eliminating feeble-mindedness by this method is not halved.

Here again we are faced by so much ignorance on this matter that it is difficult to speak with any assurance. There is an imperative need for careful study and investigation of all of these problems. Many of them would yield to a small outlay of time and money, and the answers would be clear and assuring; others of them are much more difficult, will require longer and more careful investigation. 
But in these days of scientific advancement it is unwise for us to assume that any of these are insolvable. The only wise and rational method is for us to proceed as rapidly as posssible to study these conditions, and get at fundamental facts upon which we can base our practices.

I have tried to show in this paper as briefly and concisely as possible the enormous prevalance of feeble-mindedness; (I) what feeble-mindedness is, (2) why it ought to be eliminated, (3) that it can be eliminated, and (4) how it can be eliminated. I have also not avoided the necessisty of showing that along many of these lines we still need much more data. There is absolute necessity for our studying the problem, and finding out the facts upon which our solution must depend and upon which we must act.

In conclusion, let me say that the work has been begun, and it is eminently fitting and encouraging that the American Academy of Political and Social Science has and should take up this problem, and carry it through. Society is ready for it, we are beginning to recognize the truth of the various things presented in this paper, and I believe that it only needs some person or persons, or organization to take up the matter, act as leader and guide and director in this new social movement in order to carry out a reform here which has untold value for the benefit of our present society and the humanity of the future. 